\title{
Evolution of the Journal and the Field of Organization Design
}

\author{
John Joseph(iD
}

Correspondence: johnj2@uci.edu University of California, Irvine, 4291 Pereira Dr, Irvine, CA 92617, USA

\begin{abstract}
This commentary reflects on how the themes in the Journal of Organization Design have evolved along with the field of organization design itself. Using topic modeling of abstracts, I assess the key topics or themes in the Journal of Organization Design and compare them to themes underlying design studies in mainstream management journals. I propose some mechanisms behind the differences and similarities and offer some implications for the future of the journal.
\end{abstract}

Keywords: Journal of Organization Design, Founders' imprinting, Organizational goals, Topic models

The field of organization design appears to be in a growth period. The emergence of new organizational forms (ecosystems, platforms, business models), the spread of communications and information processing technology (machine learning, artificial intelligence), and the availability of big data have all increased the attention given to organization design as an area of scientific study. The Academy of Management is seeing a greater number of sessions devoted to organization design, business schools are again offering courses on the subject, and the Journal of Organization Design (JOD) just published its 100th article (viz., Bodner and Capron 2018).

Given JOD's apparent advancements and the anecdotal evidence of a growing interest from both practitioners and the academic community, it is worth considering this question: How have the themes in JOD evolved along with the field of organization design itself? By "themes," I refer to the issues or topics that inform the published articles, which thus reflect the evolution of the journal's agenda-in terms of research priorities-and hence may serve to explain JOD's place in the field. Three key mechanisms that can articulate this relationship are founders' imprinting on JOD, this journal's organizational goals, and the themes observed in mainstream management journals.

- Founders' imprinting refers to the influence that founders' philosophies and styles of management may have on organizational identities, strategies, and action. This founders' "blueprint" is thereby reflected in "certain premises that guide decision making" later on (Baron, Hannan, and Burton 1999: 531) and may be embodied in the journal's published output.

- Organizational goals serve as both a means for evaluating alternatives and for providing alternative courses of action to organizational actors (Simon 1964). The organizational goals of a journal may therefore signal to prospective contributors

(c) The Author(s). 2018 Open Access This article is distributed under the terms of the Creative Commons Attribution 4.0 International License (http://creativecommons.org/licenses/by/4.0/), which permits unrestricted use, distribution, and reproduction in any medium, provided you give appropriate credit to the original author(s) and the source, provide a link to the Creative Commons license, and indicate if changes were made. 
that particular types of submissions are especially welcome; they may also guide efforts by editorial board members to attract new manuscripts. As articulated in this journal's “Aims and Scope," JOD's goals include publishing research by and for both academics and managers-with an emphasis on research employing future-oriented approaches (http://www.jorgdesign.net/about). Hence, JOD incorporates multiple article formats (e.g., "Point of View," "Organizational Zoo"), several of which are not found in mainstream journals.

- Themes in mainstream management journals (e.g., the Academy of Management Journal, Organization Science) reflect the field's broader research agenda. These themes tend to incorporate the dominant theoretical paradigms, methodological approaches, and/or phenomena of interest, including organization design. In the field of management, central themes in research on organization design are likely to be included in JOD's offerings because many of the same individuals sit on a number of different editorial boards and publish across journals.

\section{Methodological approach}

To assess the relationship between the themes evident in published JOD articles and the field of management more generally, I conducted a text analysis of abstracts from JOD and the top five management journals. This text analysis was based on a machine learning approach known as "probabilistic topic modeling" (Blei 2012). Topic models are algorithms that analyze the words in a set of documents to help identify the topics or themes that run through them. These algorithms are "unsupervised," which means that (i) they do not rely on human "coding" of the texts and (ii) they allow for the analysis of large collections of documents (e.g., journals, 10-K reports, patents). For a more detailed explanation of topic modeling, see Wilson and Joseph (2015).

For the purpose of this analysis, I first developed a vocabulary list (96 words) using key organization design texts (e.g., Galbraith 1974; Burton et al. 2015; Puranam 2018). This list was augmented by "stemming" the words (e.g., hierarch" $=$ hierarchical, hierarchies, hierarchy). Next, I collected abstracts from the Academy of Management Journal, the Academy of Management Review, Administrative Science Quarterly, the Journal of Organization Design, Organization Science, and the Strategic Management Journal. These abstracts were collected from the start date of each journal, and this process yielded 2273 abstracts-1495 after manual cleaning and eliminating unrelated articles.

The third step consisted of refining the vocabulary and selecting the parameters. This procedure involved the removal of "stop words" - such as "and," "or," and "of"-as well as words appearing with high frequency (because they are less relevant for distinguishing themes) or with extremely low frequency. Words were also "stemmed" (e.g., "frequenc" from "frequency" or "frequencies"). The topic model's parameters were set as follows: number of topics $K=10$; and distribution of topics $\alpha=0.01$. The latter value reflects a fairly uneven distribution of topics.

The analysis was conducted using latent Dirichlet allocation-the simplest topic model (Blei, Ng, and Jordan 2003) - and implemented in $R$. The output yielded 10 topics along with their probability of occurrence among the data set's documents (here, journal abstracts). Note that the topics so derived are simply a bundle of words. I collaborated with another researcher in assigning names to each of the topics based on their constituent words. For example, the "words" that the algorithm allocated to topic \#7 included 
"alliance," "logitudin," "interorganiz," "collabor," and "cooper." We therefore gave the name Alliances/collaboration to this topic. For each abstract, I chose the most frequently occurring topic and then summed those topics across journals to arrive at a total count of themes over the period of study. The 10 topics listed in Fig. 1 and Fig. 2 compares JOD to mainstream journals in terms of those topics.

\section{Patterns of themes observed in JOD}

There are a few patterns worth noting. Topics are distributed far more evenly across the mainstream journals than in JOD, which is not surprising given that the latter is a specialty journal. Contingency/technology/diversification is the topic appearing most frequently in the broader management field. Contingency theory, which is largely due to the work of Lawrence and Lorsch (1967) and Thompson (1967), "remains, arguably, the most influential theory of organizations to this day" (Thompson 1967: xxi).

Both Contingency/technology/diversification and Resource dependence/stakeholders are more prevalent in the overall field than in JOD. This particular difference may reflect that, by the time the latter was founded (in 2012), contingency theory and resource dependence had receded as a theoretical focus of organization design. In addition, resource dependence (unlike contingency theory) was not central to the theory of organization design.

The most prevalent topic in JOD is Fit. The journal's relatively greater emphasis on this topic may well reflect the founders' imprinting. Of course, the concept of fit was an important building block in theory construction in strategy. In particular, one of JOD's co-founders-Charles Snow-was a prolific researcher on the subject of strategy, structure, and fit (see e.g., Miles et al. 1978; Snow and Miles 1983). Borge Obel, JOD's other co-founder, authored a well-known book on the subject of fit with Richard Burton (a JOD associate editor): Strategic Organizational Diagnosis and Design: The Dynamics of Fit, first published in 2004 (Burton \& Obel, 2004), now in its third edition. Since these authors initially drew on their extended social network to attract interest and manuscripts to JOD, it is not surprising that the co-founders' own interests fueled related submissions, and the journal reinforced founding philosophies.

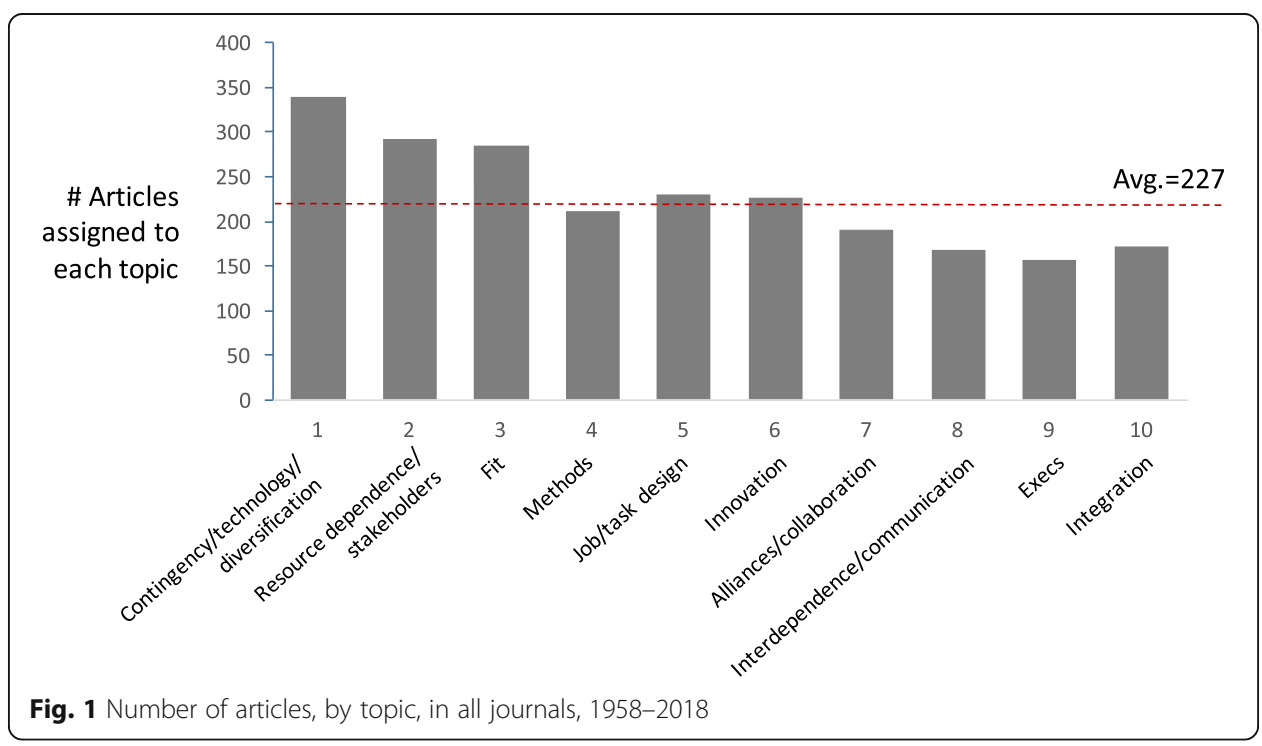




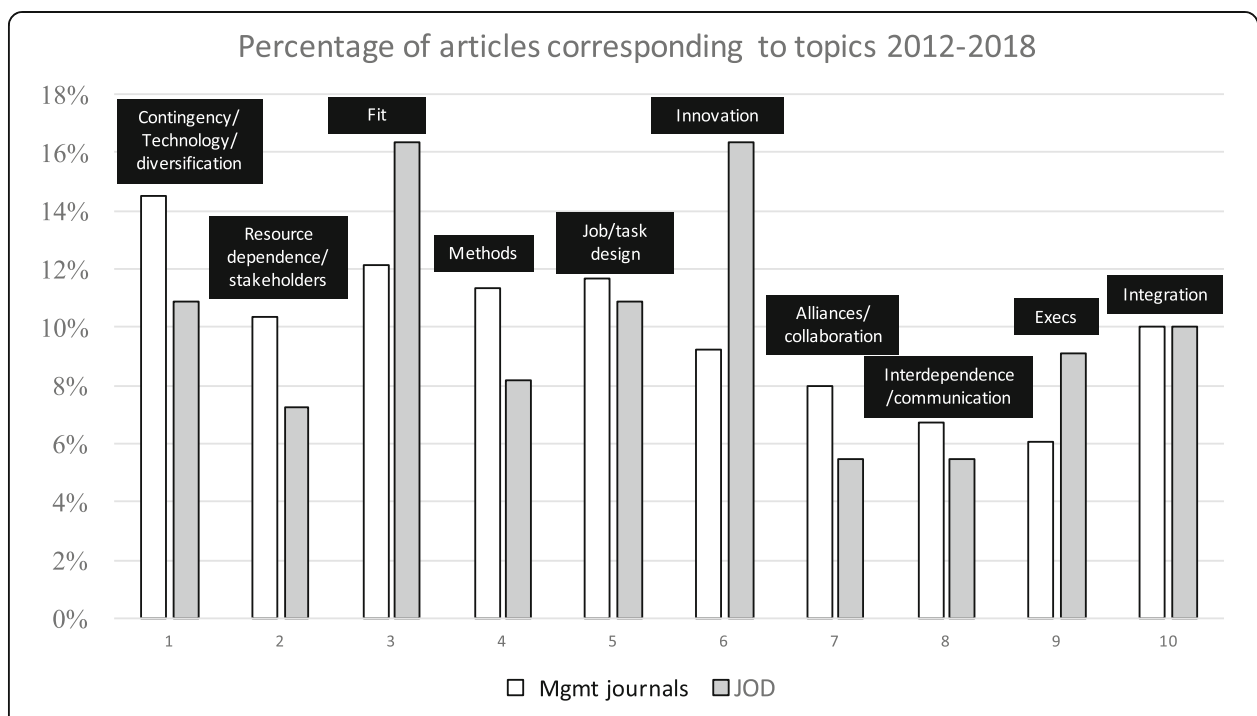

Fig. 2 Comparison of topics in JOD and mainstream management journals, 2012-2018

Two other topics that have received disproportionate attention in JOD are Innovation and Executives. Both of these topics may reflect JOD's organizational goals. Thus, the emphasis on innovation is indicative of the journal's "future" orientation and of the importance it ascribes to the relationship between organization design and technology evolution (e.g., ecosystems, platforms). In JOD's very first issue, for example, Baldwin (2012) argued that the key problem for organization design is the management of distributed innovation in dynamic ecosystems. Since then, a variety of JOD articles have focused on ecosystems, platforms, and other organizational features shaped by technology.

The greater relative emphasis that JOD places on executives reflects the journal's decision to emphasize managers as well as academics. JOD always intended to publish articles that incorporated practical concerns and addressed organizational designers, managers, and entrepreneurs who faced design problems in their own organizations. Thus, JOD is one of the few journals in the field where practitioners are reasonably well-represented among authors and editors.

Because mainstream management journals are likely to continue publishing a stream of organization design research, that trend will naturally affect the themes observed in JOD articles. However, the journal's diverse editorial board, distinct agenda (i.e., emphasis on different topics), and variety of article formats all strongly suggest that JOD will continue to deviate, to some extent, from such mainstream thematic trends. Given its structure, it is only natural that JOD will continue to provide a platform for a variety of perspectives and for the expression of design as an area of scientific inquiry that provides an important source of variation in the field of management. It is for these reasons that the Journal of Organization Design will remain an important part of the field's evolution.

Abbreviation

JOD: Journal of Organization Design 
Availability of data and materials

Journal abstract data is publically available.

\section{Declarations}

As per the submission guidelines, I attest that this paper does not share data with another under-review or published article.

\section{Author's contribution}

This is a sole-authored commentary. The author read and approved the final manuscript.

\section{Competing interests}

The author declares that he has no competing interests.

\section{Publisher's Note}

Springer Nature remains neutral with regard to jurisdictional claims in published maps and institutional affiliations.

Received: 19 July 2018 Accepted: 20 July 2018

Published online: 31 July 2018

\section{References}

Baldwin C (2012) Organization design for business ecosystems. J Organ Des 1(1):20-23

Baron JN, Hannan MT, Burton MD (1999) Building the iron cage: determinants of managerial intensity in the early years of organizations. Am Sociol Rev 64:527-547

Blei DM (2012) Probabilistic topic models. Commun ACM 55:77-84

Blei DM, Ng AY, Jordan MI (2003) Latent Dirichlet allocation. J Mach Learn Res 3:993-1022

Bodner J, Capron L (2018) Post-merger integration. J Organ Des 7:3

Burton RM, Obel B (2004) Strategic organizational diagnosis and design: the dynamics of fit, 3rd edn. Springer, New York

Burton RM, Obel B, Håkonsson DD (2015) Organizational design: a step-by-step approach, 3rd edn. Cambridge University Press, Cambridge

Galbraith JR (1974) Organization design: an information processing view. Interfaces 4(3):28-36

Lawrence PR, Lorsch JW (1967) Differentiation and integration in complex organizations. Adm Sci Q 12:1-47

Miles RE, Snow CC, Meyer AD, Coleman HJ Jr (1978) Organizational strategy, structure, and process. Acad Manag Rev 3 : $546-562$

Puranam P (2018) The microstructure of organizations. Oxford University Press, United Kingdom

Simon HA (1964) On the concept of organizational goal. Adm Sci Q 9:1-22

Snow CC, Miles RE (1983) The role of strategy in the development of a general theory of organizations. Adv Strateg Manag 2(1):213-259

Thompson JD (1967) Organizations in Action. McGraw-Hill, New York

Wilson A, Joseph J (2015) Organizational attention and technological search in the multibusiness firm: Motorola from 1974-1997. In: Gavetti G, Ocasio W (eds) Advances in strategic management: cognition and strategy. Emerald Group Publishing Limited, Bingley

\section{Submit your manuscript to a SpringerOpen ${ }^{\circ}$ journal and benefit from:}

- Convenient online submission

$\checkmark$ Rigorous peer review

- Open access: articles freely available online

- High visibility within the field

- Retaining the copyright to your article 